\title{
ELECTRIC CHARGES OF THE RED BLOOD CORPUSCLES.
}

\author{
By K. KŌSAKA and M. SEKI.
}

(From' the Anatomital Laboratory of the Okayama Medital Sthool, Okayama, Japan.)

Although the cataphoresis which the erythrocytes show in an isotonic salt or sugar solution is a well known phenomenon, yet there is no detailed information concerning this subject. Not only the erythrocytes have different electric charges according to the species of animals from which they are taken, but the effect of the surrounding fluid which determines these charges is not the same in every kind of blood. If we examine the cataphoresis of the erythrocytes in an isotonic solution under the microscope which is adjusted to a fluid layer $10-20 \mu$ from the bottom we make the following findings:

The erythrocytes of the cow and rabbit move towards the cathode in 0,9 per cent $\mathrm{NaCl}$ solution, the velocity of the migration being in rabbit much greater than in cow. On the other hand the erythrocytes of many other animals including men proceed to the anode in the same solution, the erythrocytes of the dog, cat and rat having the greatest speed, those of the pig the least. If we arrange the animals according to the direction and velocity of the cataphoresis which their erythrocytes reveal in $0,9 \% \mathrm{NaCl}$

- solution, we get the following series:

rabbit $<$ cow < pig< $<$ guinea-pig < fowl and dove $<$ man $<$ goat and mouse < rat, cat and dog

However this order is not exactly the same as the gradient of the electric charge which the erythrocytes of several animals possess in the saline solution, we must take the dimension of the erythrocytes into consideration, 
for according to LAMB's formulae ${ }^{1}$ the velocity of a charged particle through a liquid under an electric force is inversely proportional to the square of its radius, and electric charge on the particle proportional to the square of the radius. Now among the above-mentioned animals the fowl and dove have the greatest erythrocytes, next in order man, the dog and guinea-pig, the erythrocytes of the rabbit, pig and cow are of the third magnitude, those of the mouse, rat and cat the fourth, those of the goat having the least dimension. Therefore the negative charge of the goat erythrocytes must be relatively small and that of the dog erythrocytes the greatest. Nevertheless we need not take into account the dimension of the erythrocytes concerning the contact difference of potential between the corpuscles and the $\mathrm{NaCl}$ solution, so of all the observed erythrocytes, those of the cat, dog and rat stand on the most negative side and those of the rabbit on the most positive side in their potential gradient.

In $\mathrm{I}, \mathrm{I} 5$ per cent $\mathrm{KCl}$ solution and in the blood serum of the same animal the erythrocytes of the rabbit move to the cathode, those of the guinea pig to the anode as in the $\mathrm{NaCl}$ solution. In 9,5 per cent cane-sugar solution, however, the erythrocytes of all animals without exception proceed to the anode, and strange to say, the erythrocytes of the rabbit in this case move with the greatest speed, while those of the dog and cat move most slowly. If we arrange the animals according to the potential difference which occurs between their erythrocytes and the cane-sugar solution, the order is with the exception of the rat just inverse to the case of the $\mathrm{NaCl}$ solution, as seen in the following:

cat and $\operatorname{dog}<$ goat $<$ man $<$ rat $<$ guinea-pig $<$ pig $<$ cow $<$ rabbit.

The above mentioned facts were observed in the following manner. $\mathrm{A}=$ quadrilateral cell upon a slide was formed by attaching two small pieces of non-enameled porcelain and two glass strips alternately with shellack, and after washing with the $\mathrm{NaCl}$ solution the fluid containing the blood corpuscles

1. "Brit. Assn. Rep." 1887, p. 495 (Quoted from Burton's "The Physical Properties of Colloidal Solutions," 1916, p. 129). 
Fig. 1.
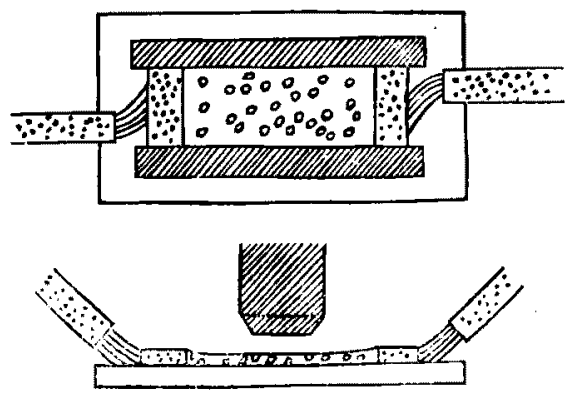

was poured in it, after which a continuous electric current was sent through the liquid by means of two non-porarisable electrodes each put on one of the non-enameled porcelain pieces (Fig. I). The movement of the erythrocytes was examined under the microscope which was always adjusted to a fluid layer $10-20 \mu$ above the bottom. Instead of the non-polarisable electrodes we used sometimes the calomel electrodes immersed directly in the fluid. In this case the erythrocytes of the cow showed a slight migration to the anode even in the $\mathrm{NaCl}$ solution. Besides we examined the movement of the erythrocytes in a $\mathbf{U}$-shaped tube filled with 5,5 per cent grape-sugar solution. In this case the erythrocytes of rabbit as well as the guinea-pig collected toward the anodic side when subjected to the influence of a continuous current. But in this experiment care must be taken to use pure blood corpuscles quite free from the blood plasma.

Now the question is, to what extent the direction of the moving erythrocytes under the microscope is determined by their electric charges, for the stream of the liquid owing to the electroendosmosis interferes to some extent with the motion of the erythrocytes, and the direction as well as the strength of $\equiv$ this stream is very different according to the depth of a fluid layer. In the layer $10-20 \mu$ above the bottom the stream of the liquid is surely directed to the cathode, so that the migration of the erythrocytes to the anode in this layer must be attributed entirely to their being negatively charged. But the movement of the erythrocytes to the cathode in this layer may be looked upon either as a simple effect of the stream or as a combined action of the 
stream and positive charge of the crythrocytes.

In order to decide this point we made the following experiment. The red blood corpuscles of the rabbit were collected by means of a centrifuge and washed with 0,9 per cent $\mathrm{NaCl}$ or 1,15 per cent $\mathrm{KCl}$ solution, and then

Fig. 2.

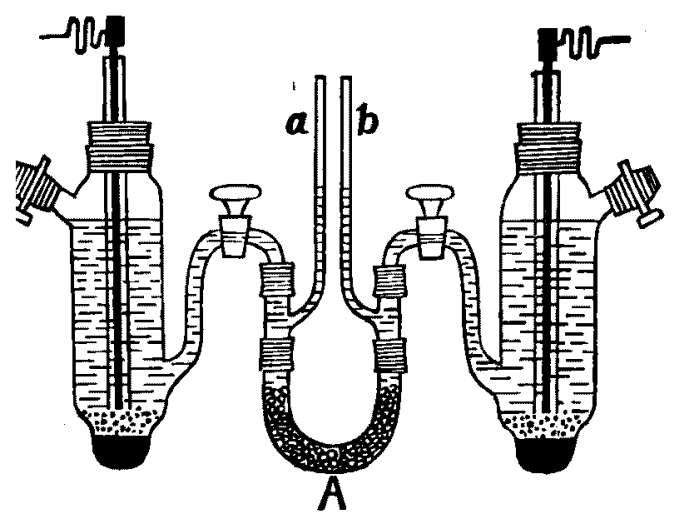

thrown into part $\mathbf{A}$ of the $\mathbf{U}$-form tube shown in fig. 2, the remaining spaces of the tube were filled with the liquid with which the blood corpuscles were washed, care being taken that no difference of level in capillaries (a and $\mathbf{b}$ ) was maintained. After some hours in which the erythrocytes had precipitated to form a fest layer, the calomel electrodes were connected with both ends of the tube, and a continuous current was sent through the liquid. The slight elevation of liquid in the capillary on the anodic side showed that the fluid made an anodic electroendosmosis. On the contrary the fluid ascended in the capillary of the cathodic side, when we used the erythrocytes of the goat instead of those of the rabbit. Therefore we believe that the erythrocytes of rabbit in the $\mathrm{NaCl}$ or $\mathrm{KCl}$ solution have a slight pasitive electric charge, unlike those of other animals. Again we tried the same experiment with the cane-sugar solution instead of the $\mathrm{NaCl}$ or $\mathrm{KCl}$ solution, 
in this case the liquid moved always tomarls the cathode, whatever erythrocytes were used.

In order to examine the cataphoresis of the erythrocytes under the microscope both $\mathrm{NaCl}$ and $\mathrm{KCl}$ solutions as well as many other salt solutions were employed. As far as the erythrocytes did not dissolve nor undergo a strong deformation the solutions of all concentration were used, so that the thickest had the concentration of one and a half isotonic solution, the thinnest being in a state approaching to cause haemolysis. $\mathrm{LiCl}, \mathrm{NaNO}_{3}$, $\mathrm{KNO}_{3}, \mathrm{Na}_{2}^{\prime} \mathrm{SO}_{4}$ or $\mathrm{K}_{2} \mathrm{SO}_{4}$ solutions had the same effect as that of $\mathrm{NaCl}$ or $\mathrm{KCl}$ solutions, namely in these solutions the erythrocytes of the rabbit moved towards the cathode quickly, those of the gront to the anode. The erythrocytes of the guinea-pig migrated to the anode too, but their velocity was very slow, and the solution of $\mathrm{K}_{2} \mathrm{SO}_{4}$ or $\mathrm{Na}_{2} \mathrm{SO}_{4}$ gave them the tendency to more towards the cathode, when the concentration of the solution was strong enough. Perhaps the motive of this tendency is caused by the fact, that the glass walls and the non-enameled porcelain piects gain a negative charge by the adsorption of bivalent anion $\mathrm{SO}_{4}^{\prime \prime}$, and as a consequence the fluid moves rapidly towards the cathode.

In each of $\mathrm{CaCl}_{2}, \mathrm{MgCl}_{2}$ and $\mathrm{SrCl}_{2}$ solutions the erythrocytes of the rabbit, guinea-pig and goat showed the cataphoresis of the same direction as in the $\mathrm{NaCl}$ solution, but their movement was vury slow. Especially this was the case with the erythrocytes of the rabbit, so that their cataphoresis was not distinctively discoverable.

In each of $\mathrm{CoCl}_{2}, \mathrm{NSO}_{4}, \mathrm{MnSO}_{4}$ and $\mathrm{MnCl}_{2}$ solutions the erythrocytes of rabbit migrated to the anode as in the sugar solution, but their velocity

玉 was less than that of the guinea-pig erythrucytes which ran in their turn less rapidly than those of the goat. Since these solutions are stronger in acidity, compared with the $\mathrm{NaCl}$ solutions of the same tension, the abovementioned phenomena may be considered partly as the effect of the acid of which we shall speak later.

The erythrocytes of the guinea-pig show no deformation in the solution of any salt of cobalt 
nickel or manganese, although they are very lialsle to a shrinkage in other solutions, whatever the osmotic pressure may be. On the other hand the erythrocytes of the rabbit become deformed a little in the former in spite of their stability in other solutions.

Solution of ammonium salts are generally too powerful as dissolvents of the erythrocytes, thereby being unfit for our purpose.

The cataphoresis which the erythrocytes of the rabbit, guinea-pig and goat show in 0,9 per cent $\mathrm{NaCl}$ solution is affected by the addition of each of the other salts, the acid and base as follows.

The addition of $\mathrm{CaCl}_{2}$ or $\mathrm{SrCl}_{2}$ or $\mathrm{MgCl}_{2}$ makes the cataphoresis generally indistinct, whereas each of $\mathrm{MnCl}_{2}, \mathrm{MnSO}_{4}, \mathrm{CoCl}_{2}$ and $\mathrm{NiSO}_{4}$ has the tendency to turn the direction of the moving erythrocytes to the anode or to make them go more swiftly to the anode. This tendency is most markedly perceptible, when the erythrocytes of the rabbit are used.

The addition of the acid should have a tendency to turn the direction of the migrating erythrocytes to the cathode or to make them go more swiftly to the cathode, while the base has just the opposite effect. We observed, however, under the microscope, that the erythrocytes in a deep fluid layer moved often diametrically oppositely to what we expected. This is due to the adsorption of the positive hydrogen ions or the negative hydroxyl ions by the slide, which must cause a strong stream in the lowest stratum of the fluid, when a continuous current is sent through it. Governed by this stream the erythrocytes move in a direction, as if the effect of the acid or base were reversed. Besides the direction of the moving erythrocytes in the upper major layer of the fluid the following experiments proved that the cataphoresis of the erythrocytes are modified by the acid in favour of the cathodic one and by the base in the contrary sense. The blood corpuscles were washed four times with a $\frac{n}{1600} \mathrm{HCl}$ or $\mathrm{NaOH}$ solution which was prepared by adding the acid or base into 9,5 per cent cane-sugar solution. With so treated blood corpuscles was stuffed the middle part (Fig. 3, A) of a convoluted tube whose entire length amounts to $80 \mathrm{~cm}$ and whose capacity $40 \mathrm{ccm}$. The remaining parts of the tube were filled with 9,5 per cent canesugar solution to which $\mathrm{NaCl}$ was added in proportion of $\frac{n}{1600}$ dilution. 
Fig. 3.

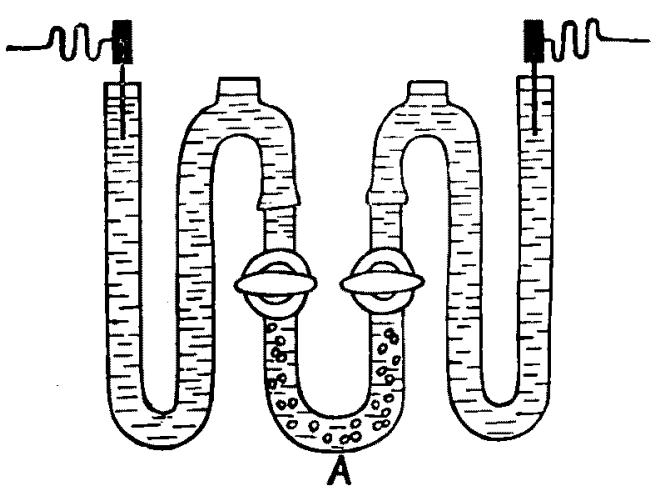

We sent a continuous current of 150 volts and $0,15 \mathrm{M}$. A. through the liquid and noticed a little shifting of the erythrocytes layer. The direction of this shifting was so, that the erythrocytes layer moved towards the cathode, if it was previously washed with the acid solution, while the same displacement occured in the opposite direction, when the base was used instead of the acid. In another experiment we used the apparatus shown in fig. 2 and examined the electroendosmosis of the fluid through the diaphragma of the rabbit erythrocytes which were previously treated with the $\mathrm{HCl}$ or $\mathrm{NaOH}$ solution. The stream was anodic in the case of $\mathrm{HCl}$ and cathodic in that of $\mathrm{NaOH}$. Instead of $\mathrm{HCl}$ and $\mathrm{NaOH}$ we employed too some mixtures of the primary and secondary phosphate which are faintly acid or alkaline in reaction according to the mixing ratio. Their effects as acid or base were $t$ the same as that of $\mathrm{HCl}$ or $\mathrm{NaOH}$.

The cataphoresis of the erythrocytes in the cane-sugar solution reveals the greater the speed the more completely the blood plasma was removed by washing the blood corpuscles with the same solution, but the erythrocytes of the rabbit proceed always most rapidly and those of the goat most slowly, while those of the guinea-pig have an intermediate velocity. On the other 
hand the electric movement of the erythrocytes becomes somewhat slower, if they are left in the cane-sugar solution for a long time (say over 24 hours). Perhaps this is due to a leakage of the electrolytes from the blood corpuscles.

If the erythrocytes are washed with the cane-sugar solution repeatedly so that they become more and more free from the adhering blood plasina, they begin finally to agglutinate. Especially the erythrocytes of the rat and guinea-pig are liable to the agglutination which occurs, however, not easily in the case of the blood corpuscles of the rabbit and goat. The agglutinated corpuscles begin to separate again, if they are conserved in the sugar solution for a long time (ca. 24 hours).

The direction and velocity of the cataphoresis, which the erythrocytes reveal in the cane-sugar solution is modified by the addition of several salts in the following tuanner: If $\mathrm{NaCl}$ or $\mathrm{KCl}$ is added to the solution in an ascending proportion until the percentage of the salts reaches 0,2 , the anodic cataphoresis of the rabbit erythrocytes turns to a cathodic one just at this point of the concentration. The addition of cupric sulphate makes the ery; throcytes of the goat and guinea-pig as well as the? rabbit go tbwards the cathode in the dilution of from $2^{2} \times 10,000$ to $2^{8} \times 10,000$ times, the velocity of the rabbit erythrocytes being most slow, and causes at the same time the agglutination of the erythrocytes. The same effect gives $\mathrm{FeCl}_{3}+3 \mathrm{H}_{2} \mathrm{O}$ to the erythrocytes of the guinea-pig in the dilution of $2 \times 10,000$ times and to those of the goat in that of $2^{2} \times 10,000$ times. $\mathrm{Fe}_{2}\left(\mathrm{SO}_{4}\right)_{3}+9 \mathrm{H}_{2} \mathrm{O}$ makes the erythrocytes of all three animals migrate to the cathode in the dilution of $2 \times 10,000$ times, and $\mathrm{Al}_{2}\left(\mathrm{SO}_{4}\right)_{3}+18 \mathrm{H}_{2} \mathrm{O}$ weakens the anodic cataphoresis of the guinea-pig erythrocytes and turns that of the goat erythrccytes to a athodic one in the dilution of 5,000 times. Since the above-mentioned salts of iron, copper and aluminium have markedly an acid reaction there is a doubt whether the stated facts may not be considered as an effect of the acid, namely whether they are not caused by a modified electroendosmosis. But we can exclude this doubt safely, for the movement of the erythrocytes is affected by the salts in a cathodic sense, while the bottom stream is forwarded by the acid in the opposite direction. Therefore we regard the result as the true effect of the metal ions. Yet there occurs a total change of 
.things, if we use the salt solutions in question in a much concentrated state, e. g. if we use a solution which is 4-10 times thicker than the above-mentioned dilution. In this case the reagents give to the agglutinated erythrocytes a tendency to move towards the anode again perhaps as consequence of a much modified electroendosmosis.

If the erythrocytes (guinea-pig, goat and rabbit) which have been several times washed with 0,9 per cent $\mathrm{NaCl}$ solution are thrown from the latter into 0,025 per cent solution of $\mathrm{MnCl}_{2}+4 \mathrm{H}_{2} \mathrm{O}$ or $\mathrm{CoCl}_{2}+{ }_{5} \mathrm{H}_{2} \mathrm{O}$ their electric charges change in such a manner, that the cataphoric movement of the negatively charged corpuscles increases, while that of the positively charged diminishes. For a while (one or two hours) this effect remains unaltered or the change increases more or less in the course of time. Especially the erythrocytes of the rabbit are by the reagents affected in a striking manner and at the same time fall into the aggiutination, although they remain electrically still on the more positive side than those of the guinea-pig and goat.

In order to know what is the cause of the electric charge of the erythrocytes which is different according to the animal species and to the nature of the surrounding fluid, we examined in the first place how the concentration of $\mathrm{H}$-ions in each of the above-mentioned solutions may change by adding the erythrocytes. For this purpose the electrometric as well as the colorimetric measurement was used. Solutions such as 0,9 per cent $\mathrm{NaCl}$, $1,15 \% \mathrm{KCl}, \mathrm{I}, 3 \% \mathrm{NaNO}_{3}, \mathrm{I}, 5 \% \mathrm{Na}_{2} \mathrm{SO}_{4}$ possess generally a $\mathrm{pH}=5,5-6,7$, if electrometrically measured. When the solutions are permitted to stand for 6 hours after the addition of the erythrocytes (rabbit, guinea-pig and goat) in the ratio of one volume to twenty of the liquid, their $\mathrm{pH}$ becomes 7,3九 7,6. In the calorimetric measurement, whereupon phenolsulphonephthalein and neutralred were used as indicators the $\mathrm{pH}$ of these solutions alone was 7,0-7,3, which became 7,35-7,5 after the addition of the blood corpuscles. Although there are some differences between the result of both measurements, it is undeniable that the addition of the erythrocytes has an effect of increasing the $\mathrm{pH}$ of the solution. The $\mathrm{pH}$ of solutions such as $2,4 \%$ 
$\mathrm{MnCl}_{2}+4 \mathrm{H}_{2} \mathrm{O}, 3.7 \% \mathrm{MnSO}_{4}+5 \mathrm{H}_{2} \mathrm{O}, 3,2 \% \mathrm{CoCl}_{2}+6 \mathrm{H}_{2} \mathrm{O}$ was electrometric-. ally $4,5-5,0$, it became $5.0-6,5$ after the addition of the erythrocytes. In the calorimetric measurement the former amounted to $6,6-6,8$, the latter to $7,4-7,5$.

Concerning 9,5\% cane-sugar and 5,5\% grape-sugar solution we examined the $\mathrm{pH}$ only by way of the colorimetric measurement. It was found, that this number ran to 7,0 in the pure solution and $7,0-7,2$ in those to which the erythrocytes were added.

The $\mathrm{pH}$ of these solutions always increases after the addition of the erythrocytes, on the other hand the alkalinity of such solutions as $\mathrm{I}, 6 \%$ $\mathrm{CaCl}_{2}, 2,2 \% \quad \mathrm{MgCl}_{2}+6 \mathrm{H}_{2} \mathrm{O}$ and $2,5 \% \quad \mathrm{SrCl}_{2}+6 \mathrm{H}_{2} \mathrm{O}$ decreases somewhat after the addition of the erythrocytes, the $\mathrm{pH}$ of these solutions originally $8,5-9,0$ in the electrometric measurement and 7,5-7,6 in the colorimetric becoming $7,0-8,0$ and $7,4-7,55$ respectively.

It is a well known fact that the proteins belonging to the amphoteric electrolytes release hydroxyl ions in an acid solution and become positively charged, while they give off hydrogen ions in an alkaline solution and are charged negatively. The fact the above-mentioned solutions of $\mathrm{CaCl}_{2}, \mathrm{MgCl}_{2}$ and $\mathrm{SrCl}_{2}$ lose somewhat their $\mathrm{pH}$ by the addition of the erythrocytes may be explained on the assumption that the erythrocytes release $\mathrm{H}$-ions in the solutions which are in turn more or less neutralized. The neutralization of the electric charges of the erythrocytes in these solutions may be reduced to a less ionized combination of the proteins with any one of the $\mathrm{Ca}-, \mathrm{Sr}-$ and Mg-ions, nevertheless something not yet explained may aid the neutralization.

It is a well known fact that the $\mathrm{pH}$ of the $\mathrm{NaCl}$ solution etc. beconing greater after the addition of the erythrocytes is due to the increase of the hydroxylions in the solution, but it is not sure whether the additional hydroxylions are derived fron the erythrocytes directly or whether indirectly from such ions as $\mathrm{HCO}_{3}{ }^{\prime}$ or $\mathrm{HPO}^{\prime \prime}$ furnished by the erythrocytes. MichneLis and TAKAHASHI ${ }^{1}$ found the isoelectric point of the stroma substance of the

I. “Biochemische Zeitschrift," I910, Vol, 29, p. 439. 
erythrocytes in the neighborhood of $\mathrm{C}_{\mathrm{H}}=1,0 \cdot 1 \mathrm{O}^{-5}(\mathrm{pH}=5)$ and Bottazz1 claims that haemoglobin's $\mathrm{H}$-ion dissóciation far exceeds its $\mathrm{OH}$-ion dissociation, hence improbality of the red corpusclus giving off hydroxyl ions in such solutions as $0,9 \% \mathrm{NaCl}, 1,1,5 \% \mathrm{KCl}, 1,3 \% \mathrm{NaNO}_{3}$ and $1,5 \% \mathrm{Na}_{2} \mathrm{SO}_{4}$, although the former two authors located the iso-electric point of oxyhaemoglobin in $\mathrm{C}_{\mathrm{H}}=1,8 \cdot 1 \mathrm{O}^{-7}(\mathrm{pH}=6,75)$.

In order to solve this problem in the case of a $\mathrm{NaCl}$ or $\mathrm{KCl}$ solution, we examined at first how many $\mathrm{Cl}$ ions were taken by the erythrocytes from the solution. We used an isotonic cane- or grape-sugar solution which contained $\mathrm{NaCl}$ or $\mathrm{KCl}$ in proportion of $\frac{m}{100}$. After the addition of the erythrocytes (rabbit, guinea-pig and goat) in the ratio of a volume to twenty of the solution it was allowed to stand an hour, and then chlorine concentration in the fluid was measured after the method of VOLHARD ${ }^{2}$, the quantity of chlorine being reduced to from $\frac{9}{10}$ to $\frac{7}{10}$ of the original. The measurement of the $\mathrm{pH}$ showed that it ascended from 7,0 to 7,4. The reduction of the chlorine quantity indicates that some $\mathrm{Cl}$-ions in the solution were taken by the erythrocytes, and we believe that this action was not due to mere adsorption but to the true penetration of $\mathrm{Cl}$-ions into the cell bodies of the erythrocytes, since these corpuscles gave back scarcely any $\mathrm{Cl}$-ions in a pure sugar solution.

Now it remains to determine whether $\mathrm{OH}^{\prime}, \mathrm{HCO}_{3}{ }^{\prime}$ or $\mathrm{HPO}_{4}^{\prime \prime}$ is produced from the erythrocytes in the greatest quantity, while $\mathrm{Cl}$-ions are taken by the latter. For this purpose $\mathrm{NaCl}$ was dissolved in the grape- or cane-sugar solution in a proportion of $\frac{m}{100}$ minus $\frac{3}{10} \times \frac{m}{100}$ and after the addition of - the same molal weight of $\mathrm{NaOH}, \mathrm{NaHCO}_{3}$ or $\mathrm{Na}_{2} \mathrm{HPO}_{3}$ to this fluid the $\mathrm{pH}$

- of the mixture was measured. This number was extraordinary great (more than 9) in the case where $\mathrm{NaOH}$ or $\mathrm{Na}_{2} \mathrm{HPO}_{1}$ was used, while it amounted to $7,6-8,0$ in the case of $\mathrm{NaHCO}_{3}$, a number which is near to 7,4 after the

1. Quoted from Bechbold's “ Die Kolloide in Biologie und Mcdizin," 1920, p. 177.

2. After Abderhalden's " Haddbuch der Biochemischen Arbeitsmethoden," 1910, Vol. 1. p. 4 17. 
additon of the erythrocytes. From these facts we deduce that some $\mathrm{Cl}$-ions in the $\mathrm{NaCl}$ or $\mathrm{KCl}$ solution enter into the erythrocytes which in turn give off some $\mathrm{HCO}_{3}$-ions.

In the above-mentioned experiments we could not find any difference in the results between the three animals, and likewise there was no difference between them, when we examined colorinetrically the $\mathrm{pH}$ of $0,9 \%$ $\mathrm{NaCl}$ solution to which tenth volume of the erythrocytes of each animal had been added severally, the $\mathrm{pH}$ being 7,35 in every case. In a later experiment the erythrocytes were allowed to stand in the solution for an hour, and then having separated them by means of the centrifuge we threw them into a new salt solution of the same percent, of course each case being treated separately. After a while the solution was separated from the containing erythrocytes and its $\mathrm{pH}$ was colorimetrically measured. In the case, where the rabbit erythrocytes were used this number ran to 7,33, while it was in the case of the goat 7,30 and in that of the guinea-pig 7,28. In another experinent of this kind we found, that there was a still greater difference between the rabbit and $\operatorname{dog}$. The $\mathrm{pH}$ of the first salt solution was, electrically measured, 7,29 in the case where the rabbit erythrocytes had been added, and 7,23 in the case of the dog. The $\mathrm{pH}$ of the second salt solution to which the erythrocytes had been carried from the first solution was 7,12 in the case of the rabbit, and in that of the dog 7,02 . These results indicate that the efficiency of the erythrocytes to raise $\mathrm{pH}$ of some solution is stronger in the rabbit than in the other animals, and this fact was more remarkably perceptible when we used an acid salt solution instead of the pure salt solution. Namely we added to one volume of the erythrocytes which lad been washed twice previously with the pure salt 三 solution ten volumes of an acid solution of $0,9 \% \mathrm{NaCl}$ cotaining $\mathrm{HCl}$ in ratio of $\frac{n}{1000}$. After a while (ca. 5 ninutes) the erythrocytes were separated from the fluid, which was later to be examined as the first solution. The separated blood corpuscles were thrown into a second portion of the sane $\mathrm{NaCl}+\mathrm{HCl}$ solution and treated exactly in the same manner as before. 
Thus we prepared first, second etc. solutions and measured their $\mathrm{pH}$ electrometrically. The result is given in the following tables. Table A shows a case where the erythrocytes of the rabbit were compared with those of the guinea-pig and goat, and table B represents another case where the comparison was made between the rabbit and dog. The asterisks show the cases where a slight haemolysis occured and therefore the result was not quite certain.

Table A.

\begin{tabular}{l|c|c|c}
\hline & Rabbit & Guinea-pig & Goat \\
\hline $\mathrm{pH}$ of first solution & $6,8 \mathrm{I}$ & 6,67 & $6,60^{*}$ \\
$\mathrm{pH}$ of second solution & 6,43 & 6,29 & $6,3^{*}$ \\
$\mathrm{pH}$ of third solution & 6,11 & 5,95 & \\
$\mathrm{pH}$ of fourth solution & 5,81 & 5,62 & \\
$\mathrm{pH}$ of ffth solution & 5,60 & $5,60^{*}$ &
\end{tabular}

Table B.

\begin{tabular}{l|c|c}
\hline & Rabbit & Dog \\
\hline $\mathrm{pH}$ of first solution & 6,79 & 6,64 \\
$\mathrm{pH}$ of second solution & 6,47 & 6,29 \\
$\mathrm{pH}$ of third solution & 6,29 & $5,59^{*}$
\end{tabular}

In addition to this we prepared two solutions of $0,9 \% \mathrm{NaCl}+\mathrm{HCl}$ one $\equiv$ of which contained $\mathrm{HCl}$ in ratio of $\frac{n}{3200}$ and the other in proportion of $\frac{n}{6400}$. To a hundred of each of these solutions we added every two volumes of the erythrocytes which had previously been washed with the pure salt solution, and once after 20 minutes, other times after an hour the pH of the solutions was colorimetrically examined. The following table gives the result. 


\begin{tabular}{|c|c|c|c|c|}
\hline & & $\begin{array}{l}\text { Concentration } \\
\text { of } \mathrm{HCl}=\frac{n}{3200}\end{array}$ & $\begin{array}{l}\text { Concentration } \\
\text { of } \mathrm{HCl}=\frac{n}{6400}\end{array}$ & $\begin{array}{l}\text { Concentration } \\
\text { of } \mathrm{HCl}=\frac{n}{6400}\end{array}$ \\
\hline & & $\begin{array}{l}\text { Measurement } \\
\text { after an hour. }\end{array}$ & $\begin{array}{c}\text { Measurement } \\
\text { after } 20 \text { minutes. }\end{array}$ & $\begin{array}{l}\text { Measurement } \\
\text { after an hour. }\end{array}$ \\
\hline it & Rabbit & 6,9 & $7, \mathbf{1}$ & 7,1 \\
\hline pH of the solutions, when & Cow & 6,9 & 7,05 & 7,05 \\
\hline following animals were & Guinea-pig & . & 7,05 & \\
\hline used. & Goat & & $7,05 ?$ & \\
\hline 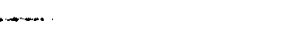 & Dog & 6,8 & $6,9+$ & - \\
\hline
\end{tabular}

From all these tables we see that the efficiency of the erythrocytes to neutralize an acid solution is the greatest in the rabbit and the least in the dog among the animals refered to. On the other hand it was found, that the efficacy of the erythrocytes to neutralize an alkaline solution is weaker in the rabbit than in the goat, guinea-pig or dog. Namely an alkaline solution of $0,9 \% \mathrm{NaCl}$ containing $\mathrm{NaOH}$ in ratio of $\frac{n}{500}$ was prepared. With this solution we made the same experiment as with the solution containing $\mathrm{HCl}$ in proportion of $\frac{n}{1000}$. The next table gives the result.

Case A.

\begin{tabular}{c|c|c}
\hline & Rabbit & Guinea-pig \\
\hline $\mathrm{pH}$ of first solution & $7,6 \mathrm{1}$ & 7,50 \\
${ }^{*} \mathrm{pH}$ of second solution & $9,5 \mathrm{I}$ & 9,26
\end{tabular}

Case B.

\begin{tabular}{c|c|c}
\hline & Rabbit & Dog \\
\hline & $\mathrm{pH}$ of first solution & $\overrightarrow{1}$ \\
\hline $\mathrm{pH}$ of second solution & $\mathbf{7 . 6 3}$ & $\mathbf{7 , 6 2}$ \\
$\mathrm{ii.} \cdot \quad \mathbf{9 , 4 1}$ & $\mathbf{9 , 2 4 *}$
\end{tabular}

Again we prepared two alkaline solution of $0,9 \% \mathrm{NaCl}$ containing $\mathrm{NaOH}$ 
in proportion of $\frac{n}{3200}$ and $\frac{n}{6400}$. To hundred of each of these solutions we threw every two volumes of the erythrocytes which had previously been washed with the pure salt solution. After an hour or an hour and half the $\mathrm{pH}$ of these solutions was measured, the result being shown in the next table.

\begin{tabular}{l|l|c|c}
\hline & $\begin{array}{c}\text { Concentration of } \mathrm{NaOH}_{2} \\
=\frac{n}{3200} \cdot\end{array}$ & $\begin{array}{c}\text { Concentration of } \mathrm{NaOH} \\
=\frac{n}{6400} \cdot\end{array}$ \\
\cline { 2 - 4 } & $\begin{array}{c}\text { Measurement } \\
\text { after an hour. }\end{array}$ & $\begin{array}{c}\text { Measurement } \\
\text { after an hour and half. }\end{array}$ \\
\hline $\begin{array}{l}\text { pH of the solutions to which } \\
\text { the erythrocytes of the fol } \\
\text { lowing animals had been } \\
\text { added. }\end{array}$ & $\begin{array}{l}\text { Rabbit } \\
\text { Guinea-pig }\end{array}$ & 7,6 & 7,5 \\
Goat & 7,55 & 7,45 \\
\end{tabular}

From all these results we are convinced, that the erythrocytes of the rabbit have a weaker efficiency to neutralize an alkaline solution than those of the dog, guinea-pig and goat.

As before mentioned some $\mathrm{Cl}$-ions are taken by the erythrocytes, if the latter have been thrown to the salt solution. Now the question is how the process may be modified by the addition of a small quantity of the acid or base to the salt solution. In order to know this we prepared two solutions which contained cane-sugar of 9.5 percentage and $\mathrm{NaCl}$ of $\frac{n}{100}$ and either $\mathrm{HCl}$ or $\mathrm{NaOH}$ of $\frac{n}{1000}$. From each of these original solutions was taken $9 \mathrm{ccm}$ to which we added every $1 \mathrm{ccm}$ of the erythrocytes which had previously been washed with the pure 9,5\% cane-sugar solution and after Io minutes the erythrocytes were separated from the liquid which was as $\overrightarrow{\text { In }}$ first solution later to be examined. The separated erythrocytes were thrown into another $9 \mathrm{ccm}$ of the concerned orginal solution and treated as before. So we got first, second etc. solutions from each of the original solution. The chlorine concentrations of all these solutions were measured after the method of VOLHARD, whereat $6 \mathrm{ccm}$ of $\frac{m}{100} \mathrm{AgNO}_{3}$ solution and $5 \mathrm{ccm}$ of the solution to be tested were always used, so that the chlorine concen- 
tration could be calculated from the variable quantity $x$ of $\frac{n}{100} \mathrm{NH}_{4} \mathrm{NCS}$ solution which had to be added until the reaction of $\mathrm{Fe}(\mathrm{NCS})_{3}$ occured. The following table gives the result, the asterisks showing the cases where a slight haemolysis occured.

Concentration of $\mathrm{Cl}$-ions in $9,5 \%$ cane-sugar,

$$
\frac{n}{100} \mathrm{NaCl} \text { and } \frac{n}{1000} \mathrm{HCl} \text { solution }=\frac{6-x}{500} n .
$$

\begin{tabular}{|c|c|c|c|}
\hline \multicolumn{3}{|c|}{ Original solution } & $\frac{5,5}{500} n$ \\
\hline Case A, & $\begin{array}{l}\text { where the orythrocytes of the rabbit } \\
\text { were washed. }\end{array}$ & $\begin{array}{l}\text { first solution } \\
\text { second solution } \\
\text { third solution } \\
\text { fourth solution }\end{array}$ & $\begin{array}{l}\frac{4,65}{500} n \\
\frac{4,7}{500} n \\
\frac{4,8}{500} n \\
\frac{4,95}{500} n^{*}\end{array}$ \\
\hline Case B, & $\begin{array}{l}\text { where the erythrocytes of the guinea-pig } \\
\text { were washed. }\end{array}$ & $\begin{array}{l}\text { first solution } \\
\text { second solution } \\
\text { third solution } \\
\text { fourth solution }\end{array}$ & $\begin{array}{l}\frac{4,6}{500} n \\
\frac{4,7}{500} n \\
\frac{5,1}{500} n^{4} \\
\frac{5,25}{500} n^{4}\end{array}$ \\
\hline Case C, & $\begin{array}{l}\text { where the erythrocytes of the goat } \\
\text { were washed. }\end{array}$ & $\begin{array}{l}\text { first solution } \\
\text { second solution }\end{array}$ & $\begin{array}{l}\frac{465}{500} n \\
\frac{4.95}{500} n *\end{array}$ \\
\hline
\end{tabular}

Concentration of $\mathrm{Cl}$-ions in $9,5 \%$ cane-sugar,

$$
\frac{n}{100} \mathrm{NaCl} \text { and } \frac{n}{1000} \mathrm{NaOH} \text { solution }=\frac{6-x}{500} \cdot n \text {. }
$$

\begin{tabular}{l|l|l}
\hline \multicolumn{2}{c|}{ Original solution } & $\frac{5,0}{500} n$ \\
\hline $\begin{array}{l}\text { Case A, where the erythrocytes of the rabbit } \\
\text { were washed. }\end{array}$ & first solution & $\frac{5,1}{500} n$ \\
$\frac{5,15}{500} n$
\end{tabular}




\begin{tabular}{|c|c|c|c|}
\hline Case A, & $\begin{array}{l}\text { where the erythrocytes of the rabbit } \\
\text { were washed. }\end{array}$ & $\begin{array}{l}\text { third solution } \\
\text { fourth solution }\end{array}$ & $\begin{array}{l}\frac{5,05}{500} n \\
\frac{4,9}{500} n^{*}\end{array}$ \\
\hline Case B, & $\begin{array}{l}\text { where the erythrocytes of the guinea-pig } \\
\text { were washed. }\end{array}$ & $\begin{array}{l}\text { first solution } \\
\text { second solution } \\
\text { third solution } \\
\text { fourth solution }\end{array}$ & $\begin{array}{l}\frac{5,15}{500} n \\
\frac{5.35}{500} n \\
\frac{5,2}{500} n \\
\frac{4,85}{500} n^{*}\end{array}$ \\
\hline Case C, & $\begin{array}{l}\text { where the erythrocytes of the goat } \\
\text { were washed. }\end{array}$ & $\begin{array}{l}\text { first solution } \\
\text { second solution } \\
\text { third solution } \\
\text { fourth solution } \\
\text { fifth solution }\end{array}$ & $\begin{array}{l}\frac{5,0}{500} n \\
\frac{5,1}{500}-n \\
\frac{5,1}{500} n \\
5,0 \\
500 \\
4,9 \\
500-n\end{array}$ \\
\hline
\end{tabular}

From these results we believe that the erythrocytes absorb some $\mathrm{Cl}$ ions in an acid salt solution, while they release these in an alkaline salt solution.

The fact that the efficiency of the erythrocytes to raise $\mathrm{pH}$ of some solutions is especially strong in the rabbit is perhaps an important factor for the fact that the erythrocytes of this animal possess a slightly positive charge in the salt solution, while those of almost all other animals are more or less negatively charged in the same solution. Likewise the fact that the - erythrocytes of the dog have a strong negative charge in the salt solution $\vec{t}$ seems to bear upon their weak efficacy to neutralize an acid solution. But this suggestion fails to give a reasonable interpretation of the fact that the velocity of the electric movement which the erythrocytes of several animals show in the sugar. solution is almost in an inverse order to that in the salt solution. To account for this fact we must have recourse to a hypothesis that the erythrocytes of such an animal as the rabbit must have a plasma 
membrane whose permeability alters greatly under certain circumstances, while this permeability of the plasma membrane is not easily liable to change on the erythrocytes of such animals as the dog or cat. If we throw the erythrocytes of the rabbit into a sugar solution which contains no electrolyte, there would occur a condensation of the cell membrane, so that it hinders the passage of some anions, while the diffusion of cations goes on unaffected. For this reason the erythrocytes of the rabbit would lose in the pure sugar solution more cations than anions and become strongly negatively charged. With erythrocytes of the dog and cat it is different. The permeability of their plasma membrane seems to remain almost unchanged in the sugar solution as well as in the salt solution, so that their negative charge is not at all raised in the sugar solution and therefore the velocity of their cataphoresis becomes in this solution relatively small.

Besides the cane-sugar solution, we employed such isotonic solutions of other non-electrolytes as 3,0\% glycerine, 5,0\% d-glucose, 5,0\% laevulose, 9.5\% lactose and $2,0 \%$ glycocoll to examine the cataphoresis of the erythrocytes of the rabbit, guinea-pig and goat. In all these solutions the erythrocytes of the rabbit proceed to the anode most swiftly and those of the goat most slowly as in the cane-sugar solution. This fact gives the information that the erythrocytes of the rabbit and guinea-pig lose more or less the permeability of the cell membrane by absence of an electrolyte in the surrounding fluid.

We turn to the problem, whether any causality exists between the hacmolysis and the electric charge of the erythrocytes. Let us consider at first the haemolysis caused by the effect of an acid. We added a drop of blood to every $2 \mathrm{ccm}$ of $\mathrm{HCl}$ solutions of different concentrations $\left(\frac{n}{200}\right.$ to $\vec{\lambda}$ $\left.\frac{n}{1600}\right)$ made up in $0,9 \% " \mathrm{NaCl}$ solution instead of in distilled water and put it for 2 hours at $37^{\circ} \mathrm{C}$ and for a further 2 hours at a room temperature in order to see to what degree haemolysis had been going on. This examination was made with blood of several animals.

The next table gives the result. 
Haemolysis which several blood samples show in $0,9 \% \mathrm{NaCl}+\mathrm{HCl}$ solutions.

\begin{tabular}{|c|c|c|c|c|}
\hline Concentration of $\mathrm{HCl}$. & $\frac{n}{400}$ & $\frac{n}{800}$ & $\frac{n}{1600}$ & $\frac{n}{3^{200}}$ \\
\hline pII of the solutions before the addition of hlood. & 2,8 & 3,16 & 3.47 & 3,86 \\
\hline Rabbit & \#+\# & 册 & - & - \\
\hline Cow & 册t & 册 & + & - \\
\hline Guinea-pig & 册 & 㱐 & 曲 & - \\
\hline Man & 册 & H\# & $H$ & - \\
\hline Goat & HA & 册 & HI & Hth \\
\hline Rat & 册 & m & 世 & + \\
\hline Dog & 册 & 删 & Hit & + \\
\hline
\end{tabular}

- represents no; + the slightest; +t stronger; tH almost complete; Hif complete haemolysis.

Further we examined the haemolysis which occured after different terms of time in several acid solutions made up in $0,9 \% \mathrm{NaCl}$ solution. In this experiment 2 drops of the blood corpuscles which had previously been washed with $0,9 \% \mathrm{NaCl}$ solution were added to $2 \mathrm{ccm}$ of each acid solution and leaving it at a room temperature we examined the process of haemolysis firstly after 16 minutes, secondly after $16 \times 2^{2}$ minutes, thirdly after $16 \times 2^{4}$ minutes and fourthly after $16 \times 2^{8}$ minutes. Each section of the following tables contains 4 columns, of which the first represents the result of the examination after 16 minutes and the second that after $16 \times 2^{2}$ minutes and so forth.

Laking of blood corpuscles in $0,9^{\circ}$ : $\mathrm{NaCl}+\mathrm{HCl}$ solutions.

\begin{tabular}{|c|c|c|c|}
\hline $\begin{array}{l}\text { pH of the solutions before the addition } \\
\text { of blood corpuscles. }\end{array}$ & 3,16 & 3,47 & 3,86 \\
\hline Erythrocytes of the rabbit & 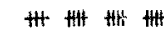 & $-H H H$ & ---- \\
\hline " "guinea-pig & 册 㖄 曲 册 & - H H H & --- \\
\hline$" \quad, \quad, \operatorname{man}$ & 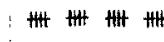 & 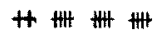 & --- \\
\hline " " " goat & 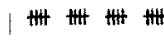 & HAt HA HAt Ht & --- \\
\hline$" \quad$ " " cat & | & Ht H H H H & --- \\
\hline
\end{tabular}


Laking of blood corpuscles in $0,9 \% \mathrm{NaCl}+\mathrm{H}_{3} \mathrm{PO}$, solutions.

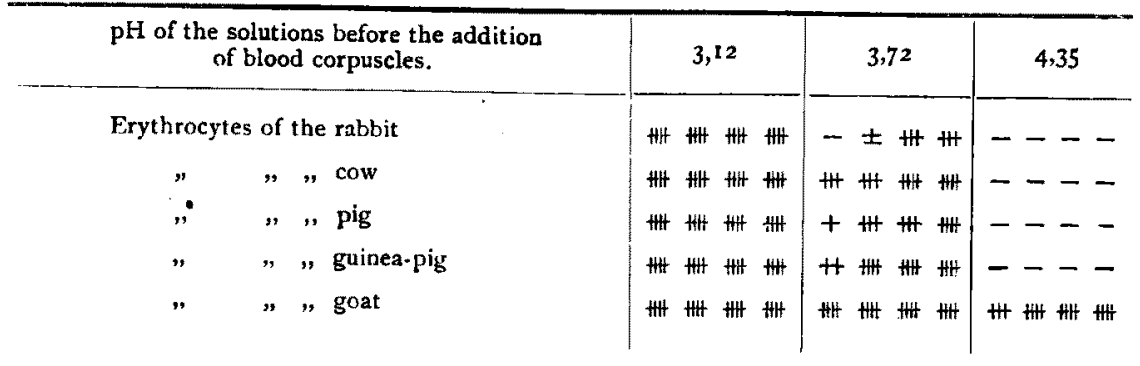

Laking of blood corpuscles in $0,9 \% \mathrm{NaCl}+\mathrm{CH}_{3}-\mathrm{COOH}$ solutions.

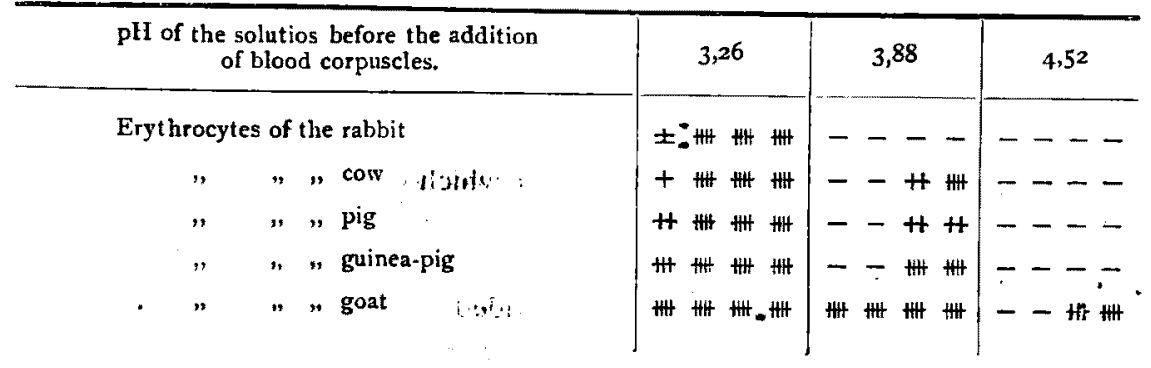

Laking of blood corpuscles in $0,9 \%$ $\mathrm{NaCl}+\mathrm{CH}_{3}-\mathrm{CHOH}-\mathrm{COOH}$ solutions.

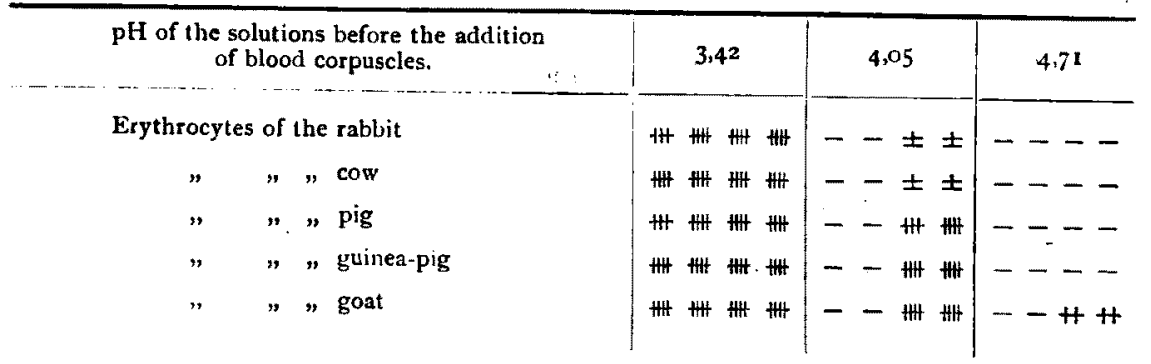

From all these results we see that the erythrocytes of the rabbit which have a strong power to neutralize an acid solution and are slightly positively, charged in $0,9 \% \mathrm{NaCl}$ solution resist the haemolytic effect of the acid most obstinately compared with the erythrocytes of the other animals. On the other hand it is certain that the erythrocytes of the goat which show 
in $0,9 \% \mathrm{NaCl}$ solution relatively a strong negative potential are most liable to the haemolysis caused by the acid. With regard to other erythrocytes we can not say anything definitely, but generally speaking it seems probable that erythrocytes which are strongly negatively charged in the $\mathrm{NaCl}$ solution dissolve easily in an acid solution, while those of a weak negative charge are less liable to haemolysis. The statement does not hold, however, for an acid solution in which some substance acts as "buffer" in order that the acidity of the solution may be kept at a uniform level. In such solutions of reserve acidity the erythrocytes of the rabbit are most liable to haemolysis, while those of the goat and dog resist the haemolytic effect of the acid very markedly at least during the first few hours, as witnessed in the following experiment. Namely we made up solutions of $\mathrm{H}_{3} \mathrm{PO}$, of different concentrations in $3 \% \quad \mathrm{KH}_{2} \mathrm{PO}$, solution and added to every $2 \mathrm{ccm}$ of these solutions 2 drops of the blood corpuscles which had previously been washed with $0,9 \% \mathrm{NaCl}$ solution. As in the former experiment the examination was made 1. after 16 minutes, 2. after $16 \times 2^{2}$ minutes, 3. after $16 \times 2^{4}$ minutes and 4. after $16 \times 2^{\mathrm{s}}$ minutes. The results of these four examination are given in 4 columns of each section of the next table.

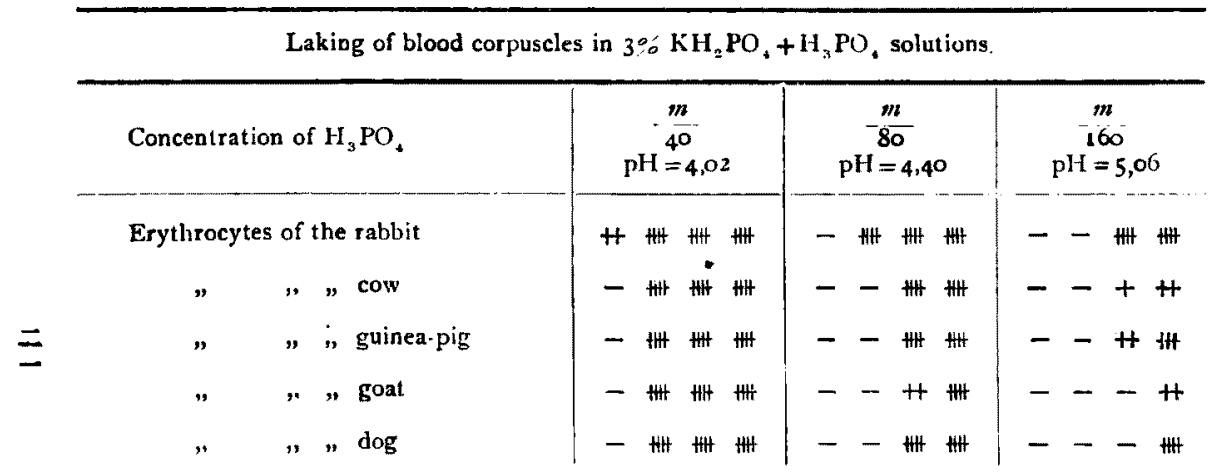

But in the case where $\mathrm{H}_{3} \mathrm{PO}_{4}$ solutions of very low concentrations were used we found that the erythrocytes of the rabbit were less liable to haemolysis than those of the cow and dog, as the result given in the next table. 


Haemolysis in $\mathrm{H}_{3} \mathrm{PO}$, solutions of very low concentrations made up in $3 \% \mathrm{KH}_{2} \mathrm{PO}$, solution.
Concentration of $\mathrm{H}_{\mathrm{a}} \mathrm{PO}$,
Erythrocytes of the rabbit
" " cow
From the first to the fourth columns of each section represent the results after from 4
to $4 \times 2^{5}$ minutes; the fifth the result after $4 \times 2^{\circ}$ minutes.

The reason why the erythrocytes of the rabbit in the solution of $3 \%$ $\mathrm{KH}_{2} \mathrm{PO}_{4}+\mathrm{H}_{3} \mathrm{PO}_{4}$ are less liable to haemolysis than those of the cow and dog as in an acid $\mathrm{NaCl}$ solution is that the solutions are easily neutralized by the erythrocytes owing to the very low concentrations of $\mathrm{H}_{3} \mathrm{PO}_{4}$ and soon lose the quality of reserve acidity.

Concerning the haemolysis caused by the effect of the base we made the following experiment. $\mathrm{NaOH}$ solutions of different concentrations were made up in $0,9 \% \mathrm{NaCl}$ solution instead of in distilled water and a drop of blood was added to $2 \mathrm{ccm}$ of each of these solutions. Then we put it for 2 hours at $37^{\circ} \mathrm{C}$ and for another period of 2 hours at a room temperature to know the process of haemolysis. This examination was tried with several samples of blood. The next table shows the result.

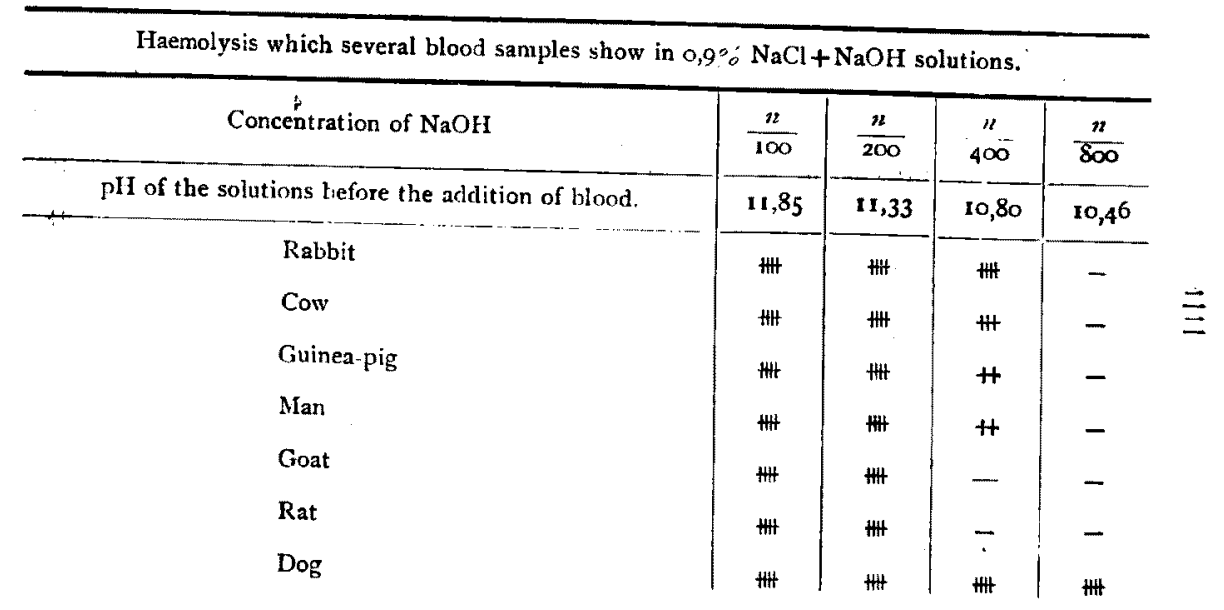


From this table we see that the erythrocytes of the dog are most easiiy destroyed by the alkaline solution. They seem to be especially susceptible to the effects of the base. With this exception the erythrocytes of the rabbit which showed the greatest resistance in the acid solution are here most liable to haemolysis, while those of the goat and rat, which offered the least resistance to the acid remain here most unaffected. And a general rule seems to prevail that less negatively charged erythrocytes in the $\mathrm{NaCl}$ solution are more liable to the haemolytic effect of the base, except the special case of the dog.

Now we proceed to deal with the question whether there exists any relation between the electrochemical series of the elements and their haemolytic effect. Those elements which possess lower solution pressures than hydrogen have generally a strong power to cause haemolysis or to destroy the erythrocytes. In order to test this fact we used several compounds of such elements as $\mathrm{Cu}, \mathrm{Hg}, \mathrm{Ag}, \mathrm{Pt}, \mathrm{Au}, \mathrm{Sb}$ and $\mathrm{As}$ all possess lower solution pressure than hydrogen. Each of these compounds expect $\mathrm{AgNO}_{3}$ was dissolved in $0,9 \% \mathrm{NaCl}$ solution in the form of very weak concentrations, and 2 drops of the erythrocytes which had previously been washed with the pure $\mathrm{NaCl}$ solution were thrown into $2 \mathrm{ccm}$ of each solution. It was allowed to stand at a room temperature and after $16,16 \times 2^{2} ; 16 \times 2^{4}$ and $16 \times 2^{8}$ minutes we examined the process of haemolysis. This experiment was repeated with several blood samples. In the case where $\mathrm{AgNO}_{3}$ was used we washed the erythrocytes with $1,35 \% \quad \mathrm{NaNO}_{3}$ solution and then threw them into a solution of $\mathrm{AgNO}_{3}$ which was also nade up in the new - $\mathrm{NaNO}_{3}$ solution.

झ In the following table some cases are shown where the laking or destruction of the erythrocytes occured within $16 \times 2^{4}$ minutes; 1. - 3 . columns represent the results after $16,16 \times 2^{2}$ and $16 \times 2^{4}$ minute: 
Destruction of blood corpuscles in thin copper salts solutions made up in $0,9 \% \mathrm{NaCl}$ solution.

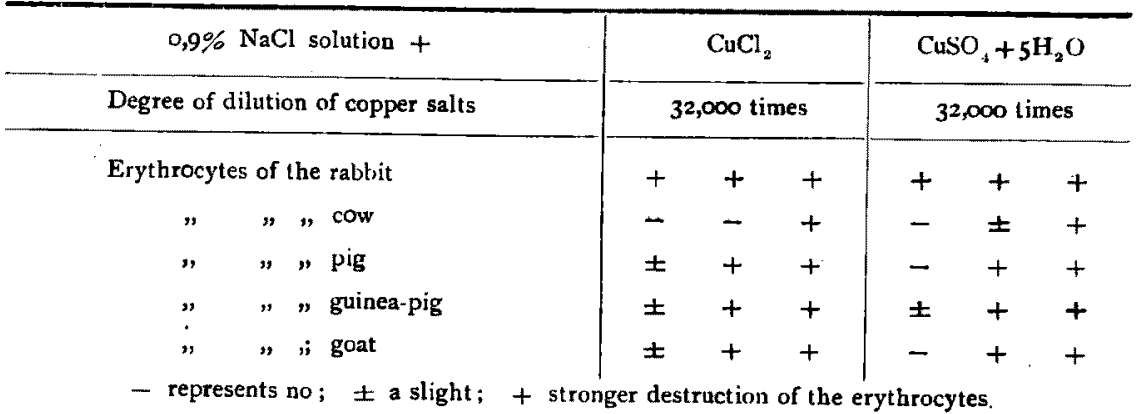

Laking of the erythrocytes in thin mercury salts solutions made up in $0,9 \% \mathrm{NaCl}$ solution.

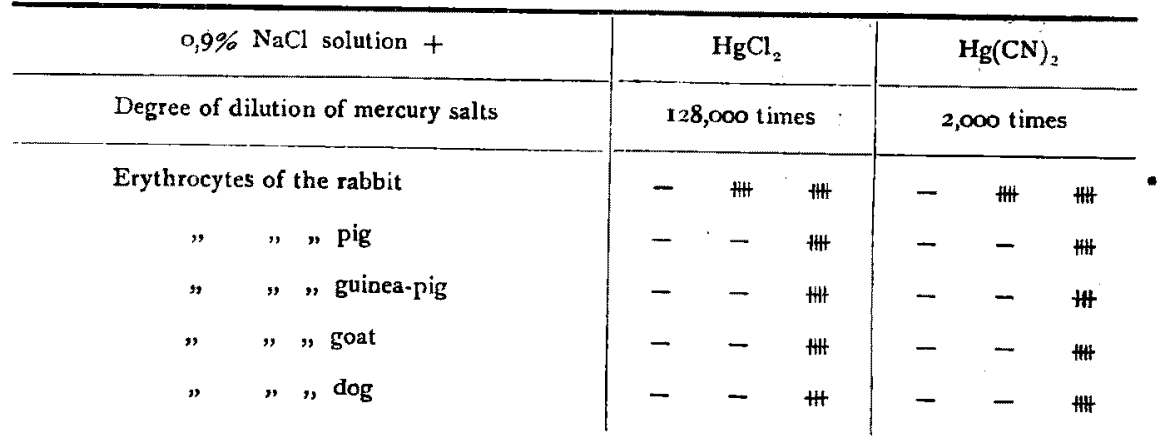

Laking of the erythrocytes in thin silver compounds solutions made up in $1,35 \% \mathrm{NaNO}_{3}$ or $0,9 \% \mathrm{NaCl}$ solution.

\begin{tabular}{|c|c|c|c|c|c|c|c|}
\hline & & \multicolumn{3}{|c|}{$\begin{array}{c}1,35 \% \mathrm{NaNO}_{3}+\mathrm{AgNO}_{3} \\
\text { solution }\end{array}$} & \multicolumn{3}{|c|}{$\begin{array}{l}0,9 \% \text { NaCl}+ \text { Xytargol } \\
\text { (prepared by Kisrida) }\end{array}$} \\
\hline \multicolumn{2}{|c|}{ Degree of dilution of silver compounds } & \multicolumn{3}{|c|}{256,000 times } & \multicolumn{3}{|c|}{8,000 times } \\
\hline \multicolumn{2}{|c|}{ Erythrocytes of the rabbit } & 册t & HHF & \# & \pm & 世 & HA \\
\hline$"$ & $"$ " cow & $H$ & HW & $\#$ & - & + & 册 \\
\hline$"$ & $"$, pig & H & 姗 & 曲 & - & H & Htt \\
\hline$"$ & " "guinea-pig & Htt & 世 & 册 & - & + & 册 \\
\hline$"$ & $"$ " goat & - & + & $H$ & - & - & \pm \\
\hline
\end{tabular}




\begin{tabular}{|c|c|c|c|c|c|c|c|}
\hline \multicolumn{8}{|c|}{$\begin{array}{l}\text { Laking of the erythrocytes in thin auric and platinic chloride solutions made up } \\
\text { in } 0,9 \% \mathrm{NaCl} \text { solution. }\end{array}$} \\
\hline \multicolumn{2}{|c|}{$0,9 \% \mathrm{NaCl}$ solution +} & \multicolumn{3}{|c|}{$\mathrm{AuCl}_{3}+4 \mathrm{H}_{3} \mathrm{O}$} & \multicolumn{3}{|c|}{$\mathrm{PtCl}_{+}+5 \mathrm{H}_{2} \mathrm{O}$} \\
\hline \multicolumn{2}{|c|}{ Degree of dilution of auric and platinic chloride. } & \multicolumn{3}{|c|}{ I 28,000 times } & \multicolumn{2}{|c|}{8,000 times } & $\mathrm{pH}=4,06$ \\
\hline \multicolumn{2}{|c|}{ Erythrocytes of the rabluil } & \pm & HHt & Hit & - & 世 & HW \\
\hline$"$ & $"$ " cow & - & - & Ht & - & - & 怆 \\
\hline " & " "pig & - & \pm & 卌 & - & - & \pm \\
\hline & ", guinea-pig & - & - & $H$ & - & - & HI \\
\hline " & $"$ " goat & - & - & H & - & - & Hil \\
\hline
\end{tabular}

Laking of the erythrocytes in a thin arsenic compound solution made up in $0,9 \% \mathrm{NaCl}$ solution.

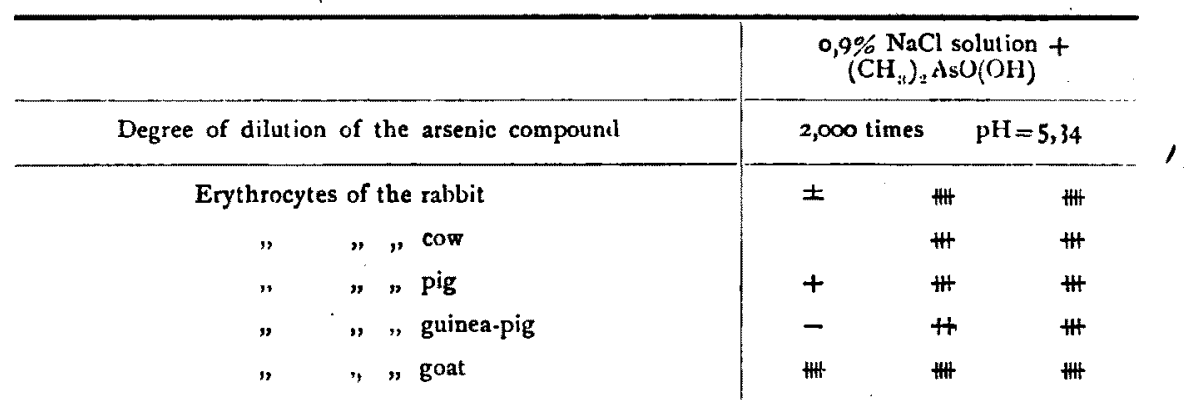

In the solution of antimony compound of weak acidity we could nct find a destruction of the erythrocytes of the rabbit within $16 \times 2^{4}$ minutes, but the fact that this element has likewise a strong haemolytic effect is seen in the next table.

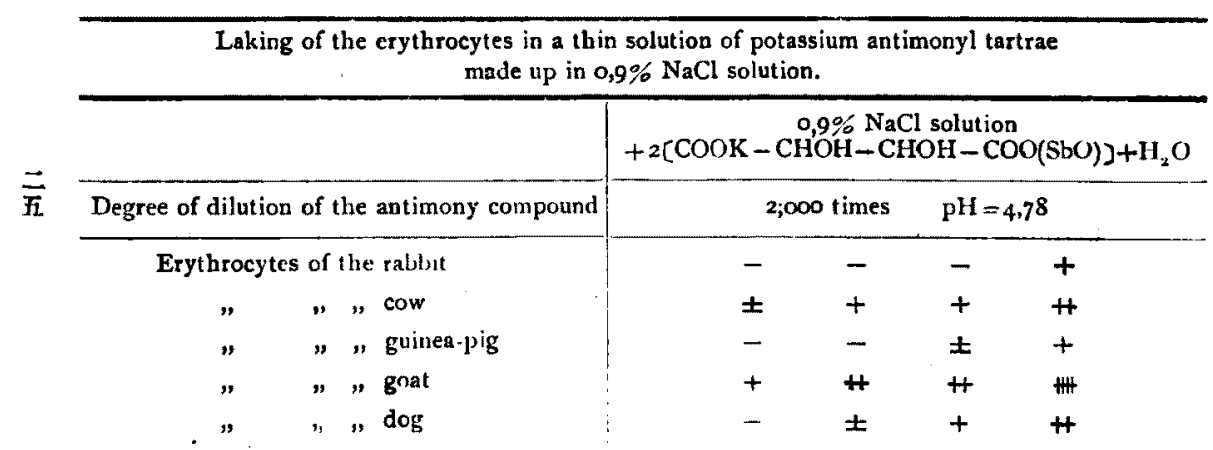

1.-4. columns represent the results after $16,16 \times 2^{2}, 16 \times 2^{4}$ and $16 \times 2^{*}$ minutes. 
From the above tables alone the less negatively charged erythrocytes șeen to be more liable to haemolysis in solutions of the copper, mercury, silver, gold or platinum compounds. This tendency is seen more clearly, when we use thinner solutions, as seen in the next tables.

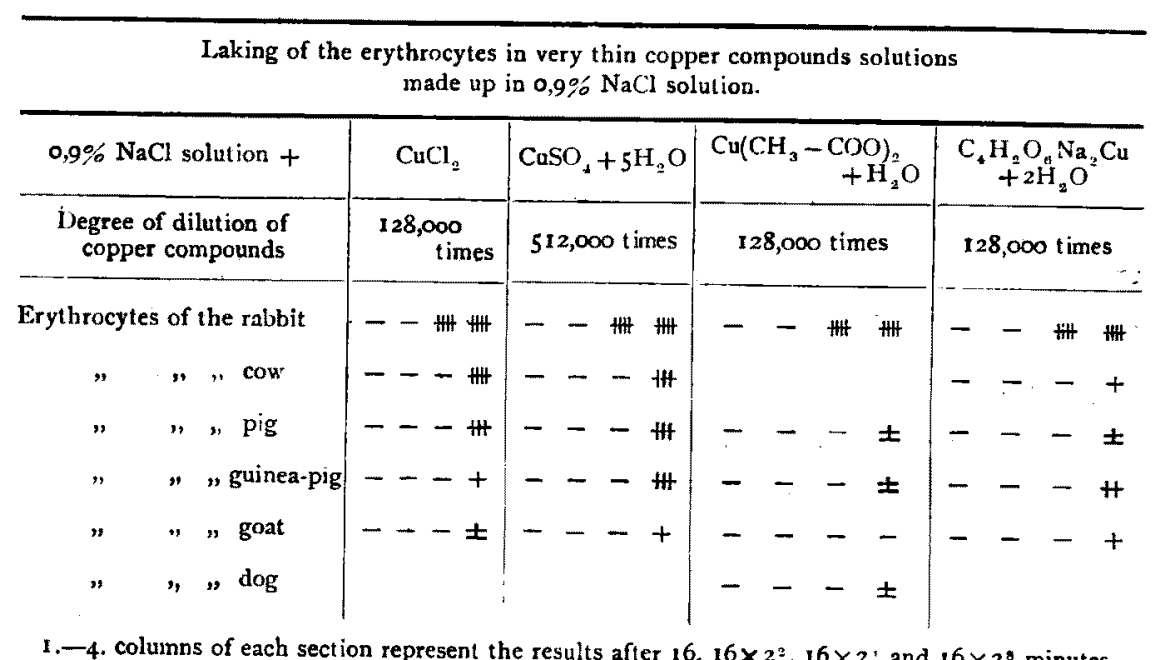

1,-4. columns of each section represent the results after $16,16 \times 2^{2}, 16 \times 2^{\prime}$ and $16 \times 2^{8}$ minutes.

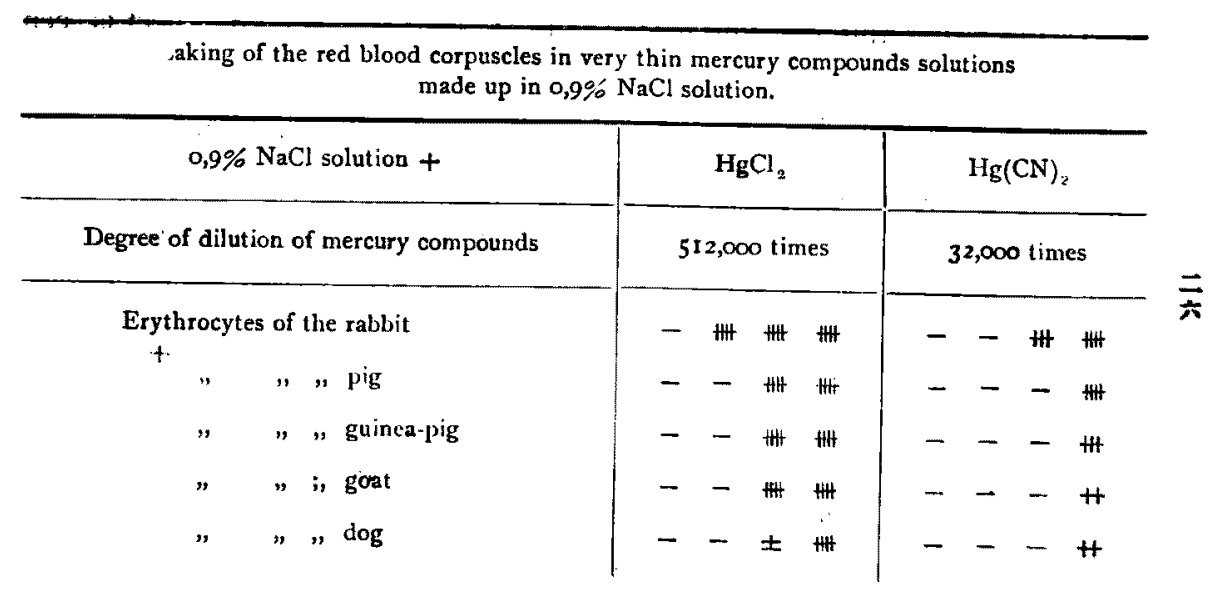


Laking of the red blood corpuscles in very thin silver compounds solutious made up in $1,35 \% \mathrm{NaNO}_{3}$ or $0,9 \% \mathrm{NaCl}$ solution.

\begin{tabular}{|c|c|c|c|c|c|c|c|c|c|c|c|c|c|}
\hline & & \multirow{2}{*}{\multicolumn{4}{|c|}{$\frac{\begin{array}{c}1,35 \% \mathrm{NaNO}_{3}+\mathrm{AgNO}_{3} \\
\text { solution }\end{array}}{1,024,000 \text { times }}$}} & \multicolumn{4}{|c|}{$\begin{array}{l}0,9 \% \mathrm{NaCl} \\
+ \text { Protargol }\end{array}$} & \multicolumn{4}{|c|}{$\begin{array}{l}0,9 \% \mathrm{NaCl} \\
+ \text { Xytargol }\end{array}$} \\
\hline \multicolumn{2}{|c|}{$\begin{array}{l}\text { Degree of dilution of } \\
\text { silper compounds }\end{array}$} & & & & & \multicolumn{4}{|c|}{32,000 times } & \multicolumn{4}{|c|}{32,000 times } \\
\hline \multicolumn{2}{|c|}{ Erythrocytes of the rabbit } & 冊 & 册 & m. & 册 & & H & Hit & & + & H & mtt & 册 \\
\hline$"$ & $"$ " cow & \pm & $H$ & Htt & Ht & - & - & \pm & tht & - & - & $H$ & HH \\
\hline י & " " pig & + & $H$ & 册 & 册 & - & - & $\#$ & .tH & - & - & \pm & $H$ \\
\hline "' & " " guinea-pig & \# & 世 & 册 & m & - & - & $H$ & 卅 & - & - & \pm & th \\
\hline & " " goat & - & - & - & H & $-:$ & - & - & 半 & - & - & - & + \\
\hline
\end{tabular}

Laking of the erytbrocytes in very thin auric and platinic chloride solutions made up in $0,9 \% \mathrm{NaCl}$ solution.

\begin{tabular}{|c|c|c|c|c|c|c|c|c|c|}
\hline \multicolumn{2}{|c|}{$0,9 \% \mathrm{NaCl}$ solution +} & \multicolumn{4}{|c|}{$\mathrm{AuCl}_{3}+{ }_{4} \mathrm{H}_{3} \mathrm{O}$} & \multicolumn{4}{|c|}{$\mathrm{PtCl}_{4}+5 \mathrm{H}_{2} \mathrm{O}$} \\
\hline \multicolumn{2}{|c|}{ Degree of dilution of auric and platinic chloride } & \multicolumn{4}{|c|}{$256, \infty 00$ times } & \multicolumn{4}{|c|}{32,000 times } \\
\hline \multicolumn{2}{|c|}{ Erythrocytes of the rabbir } & & H & 册 & H & - & - & \pm & HA \\
\hline " & $"$, cow & & & & & - & - & - & H \\
\hline & " pig & - & - & \pm & 册 & - & - & - & H \\
\hline & ", guinea-pig & - & \pm & 册 & H & - & - & - & H \\
\hline & ", goat & - & - & - & H & - & - & - & H \\
\hline & , , dog & & - & - & \# & & & & \\
\hline
\end{tabular}

Those elements which possess higher solution pressures than hydrogen $\overline{\bar{t}}$ have generally only a weak haemolytic effect or none at all. We demonstrated this fact by using isotonic solutions of such salts as $\mathrm{KCl}, \mathrm{NaCl}, \mathrm{LiCl}$, $\mathrm{CaCl}_{2}, \mathrm{SrCl}_{2}, \mathrm{BaCl}_{2}, \mathrm{MgCl}_{2}, \mathrm{ZnSO}_{4}, \mathrm{CdSO}_{4}, \mathrm{MnCl}_{2}, \mathrm{FeCl}_{2}, \mathrm{CoCl}_{2}, \mathrm{NiCl}_{2}$ and $\mathrm{Pb}\left(\mathrm{NO}_{\mathrm{g}}\right)_{2}$. To $2 \mathrm{ccm}$ of each of these solutions was added a drop of the erythrocytes which had previously been washed with $0,9 \% \mathrm{NaCl}$ solution, except the case of the $\mathrm{Pb}\left(\mathrm{NO}_{3}\right)_{2}$ solution, where the erythrocytes had been 
washed with $1,4 \% \quad \mathrm{NaNO}_{3}$ solution instead of the $\mathrm{NaCl}$ solution. It was allowed to stand at a room temperature of $20^{\circ}-25^{\circ} \mathrm{C}$ and after 12 hours the examination was made. The next table represents the result.

\begin{tabular}{|c|c|c|c|c|c|c|c|c|c|c|}
\hline \multicolumn{3}{|c|}{ Erythrocytes of the } & rabbit & cow & pig & $\begin{array}{c}\text { guinea- } \\
\text { pig }\end{array}$ & $\operatorname{man}$ & goat & $\operatorname{dog}$ & cat \\
\hline \multicolumn{3}{|c|}{$1,15 \%$ solution of $\mathrm{KCl}$} & $\dot{ \pm}$ & - & - & \pm & - & - & 世 & Hit \\
\hline $0,9 \%$ & $"$ & $" \mathrm{NaCl}$ & - & - & - & - & - & - & \pm & - \\
\hline $1,2 \circ$ & " & " $\mathrm{LiCl}+2 \mathrm{H}_{2} \mathrm{O}$ & + & $H$ & - & \pm & - & - & + & - \\
\hline $1,6 \%$ & $"$ & ${ }_{n} \mathrm{C}_{2} \mathrm{Cl}_{2}$ & + & - & \pm & H & \pm & - & \# & - \\
\hline $2,5 \%$ & $"$ & $=\mathrm{SrCl}_{2}+6 \mathrm{H}_{3} \mathrm{O}$ & 世 & - & - & $H$ & + & - & 册 & \pm \\
\hline $2,4 \%$ & . & $=\mathrm{BaCl}_{2}+2 \mathrm{H}_{2} \mathrm{O}$ & - & - & - & $H$ & \pm & - & H & - \\
\hline $2,3^{\circ}$ & ", & " $\mathrm{MgCl}_{2}+6 \mathrm{H}_{3} \mathrm{O}$ & $H$ & - & \pm & + & - & - & + & - \\
\hline $4,0 \%$ & $"$ & $=\mathrm{ZnSO}_{1}+7 \mathrm{H}_{2} \mathrm{O}$ & - & - & - & - & - & - & - & - \\
\hline $7,0 \%$ & $"$ & " $\operatorname{CoS}()_{1}+8 \mathrm{H}_{2} \mathrm{O}$ & - & - & \pm & \pm & - & - & - & - \\
\hline $2,4^{\circ} \circ$ & ., &, $\mathrm{MnCl}_{2}+4 \mathrm{H}_{2} \mathrm{O}$ & - & - & - & - & - & - & $H$ & - \\
\hline $2,4^{\circ}$ & $"$ & , $\mathrm{FeCl}_{2:}+4 \mathrm{HI}_{2} \mathrm{O}$ & - & - & - & - & - & - & - & - \\
\hline $3.2^{\circ}$ & $"$ & $" \mathrm{CuCl}_{2}+6 \mathrm{H}_{2} \mathrm{O}$ & - & - & - & itit & - & $-{ }_{n}$ & : & - \\
\hline $3.2^{\circ}$ & " & $" \mathrm{NiCl}_{2}+6 \mathrm{H}_{2} \mathrm{O}$ & - & - & - & - & - & - & $\dot{-}$ & - \\
\hline $60^{\circ}$ & $"$ & $" \mathrm{~Pb}\left(\mathrm{NO}_{3}\right)_{4}$ & - & - & - & \pm & - & - & - & - \\
\hline
\end{tabular}

While the bivalent cation $\mathrm{Fe}$ " has no power to cause haemolysis as seen in the above table, the trivalent cations $\mathrm{Fe}^{\cdots \cdot *}$ and $\mathrm{Al}^{\cdots \cdots}$ with a very great power in the precipitation of sols possess a strong haemolytic effect, which resembles that of the acid. Indeed in thin solutions of ferric and aluminium compounds made up in $0,9 \% \mathrm{NaCl}$ solution are the erythrocytes of the goat with a strong negative potential most liable to haemolysis, while those of the rabbit with a positive charge remain most unaffected, as shown in the next table. 


\begin{tabular}{|c|c|c|c|c|c|c|c|c|c|c|c|c|}
\hline \multicolumn{13}{|c|}{$\begin{array}{c}\text { Laking of the erythrocytes in thin ferric and aluminium salts solutions } \\
\text { made up in } 0,9,9^{\prime} \mathrm{NaCl} \text { solution. }\end{array}$} \\
\hline \multicolumn{2}{|c|}{$0,9 \% \mathrm{NaCl}$ solution +} & \multicolumn{3}{|c|}{$\mathrm{Fe}_{2}\left(\mathrm{SO}_{4}\right)_{3}+9 \mathrm{H}_{2} \mathrm{O}$} & \multicolumn{4}{|c|}{$\mathrm{Al}_{2} \mathrm{~K}\left(\mathrm{SO}_{4}\right)_{4}+24 \mathrm{H}_{2} \mathrm{O}$} & \multicolumn{4}{|c|}{$\begin{array}{c}\mathrm{Al}_{2}\left(\mathrm{SO}_{*}\right)_{3}+\mathrm{I}_{2} \mathrm{H}_{2} \mathrm{O} \\
\begin{array}{c}4,000 \text { times } \\
\mathrm{HI}=5,35\end{array}\end{array}$} \\
\hline \multicolumn{2}{|c|}{$\begin{array}{l}\text { Degree of dilution of ferric and } \\
\text { aluninium compounds }\end{array}$} & \multicolumn{3}{|c|}{$\begin{array}{l}8,000 \text { times } \\
\mathrm{pH}=4,7^{2}\end{array}$} & \multicolumn{4}{|c|}{$\begin{array}{l}2,000 \text { times } \\
\mathrm{p} L 1=5,13\end{array}$} & & & & \\
\hline Erythroc & of the rabbit & & - & $-H$ & - & - & - & - & - & - & - & - \\
\hline & $" \quad n$ cow & & + & +4 & - & - & \pm & + & - & - & + & + \\
\hline " & ", , pig & \pm & + & $+H$ & - & \pm & + & $H$ & - & - & \pm & + \\
\hline$"$ & $"$ "guinea-pig & $H$ & $H$ & HH Ht & - & - & H & 册 & - & - & + & \# \\
\hline$"$ & " " goat & \# & Hat & HI $\quad$ Ht & H H & HI & Ht & HA & $H$ & $H$ & \# & \# \\
\hline
\end{tabular}

These results were obtained in the same manner as in the case of the copper, mercury etc. solutions.

The haemolytic effect of saponin, natrium oleat and alcohol has no bearing on the electric charge of the erythrocytes and seems to be chiefly concerned with the action to dissolve the lipoid. By adding these substances to a $0,9 \% \mathrm{NaCl}$ solution which contained the erythrocytes we found that the exythrocytes of the dog, rabbit and guinea-pig were more liable to haemolysis than those of the goat and cow, a result which is in accordance with Rywosch's'. Moreover we ascertained that the cataphoresis of the erythrocytes revealed no change by the addition of saponin. Again the haemolysis caused by hypotonic solutions has no relation to the electric charge of the erythrocytes. By adding the erythrocytes preserved in $0,9 \% \mathrm{NaCl}$ solution at $2^{\circ}-6^{\circ} \mathrm{C}$ for 20 hours into hypotonic $\mathrm{NaCl}$ solutions of different concentrations $(0,3 \%-0,6 \%)$ we found that the difference of resistance $\vec{\imath}$ towards haemolysis between the erythrocytes of different animals was is the following series:

\section{Guinea-pig $>$ man $>$ rabbit $>$ dog $>$ rat $>$ cow $>$ goat}

This result agrees in part with Ryivosch's. According to HAmburger ${ }^{2}$

1. "Pfliger's Archiv," 1907, Vol, 116, p. 229.

2. “Archiv für Physiologie," I 898, p. 3 1. 
the resistance of the erythrocytes towards hypotonic $\mathrm{NaCl}$ solutions is incrased by the effect of the alkali. In order to prove this conclusion we added a very small quantity of sodium hydroxide to each of $0,9 \% \mathrm{NaCl}$ solutions which contained the erythrocytes of the goat, guinea-pig or rabbit. It was allowed to stand more than an hour and then we threw the erythrocytes into hypotonic solutions. In this experiment we found that the goat erythrocytes with a strong negative potential showed a remarkable increase of resistant power, and next in order those of the guinea-pig, while the positively charged erythrocytes of the rabbit seemed to have obtained no such change or rather a slight decrease of resistance. On the other hand the resistance of the erythrocytes towards hypotonic $\mathrm{NaCl}$ solutions is decreased by the effect of the acid (Hamburger). To confirm this conclusion we nuade the same experiment as before, except that wi used $\mathrm{HCl}$ instead of $\mathrm{NaOH}$ and found that here too the erythrocytes of the goat were most affected, while those of the rabbit showed the least change in the above sense. Besides the acid we found that $\mathrm{MnCl}_{2}, \mathrm{CoCl}_{2}$ and $\mathrm{NiSO}_{4}$ very markedly decrease the resistance of the erythrocytes towards hypotonic solutions. But the effect of these salts may be due to the acid, for solutions of all these salts have a strong acid reaction. In fact we found that the effect of such solutions as $0,25 \% \mathrm{MnCl}_{2}(\mathrm{pH}=5,07), 0,025 \% \mathrm{CoCl}_{2}(\mathrm{pH}=4,9)$ and $0,025 \% \mathrm{NiSO}_{4}(\mathrm{pH}=4,73)$ were stronger than that of a $\mathrm{HCl}$ solution whose $\mathrm{pH}$ is 4,38 , yet this fact may be duc to an effect of these salt solutions which perhaps possess the quality of a "buffer."

Finally we should like to make a few remarks upon the question how the electric charge of the erythrocytes is influenced by the haemolytic serum. Normal rabbit's or goat's serum may be mixed with the erythrocytes of the guinea-pig without causing any change to the charge of the latter. If, however, we use the serum of a rabbit to which guinea-pig's corpuscles have been injected at intervals of a few days, the erythrocytes will show a phenomenon of agglutination and move to the cathode instead of to the anode. The same condition is found, when we heat the haemolytic serum at $56^{\circ} \mathrm{C}$ 
for 30 minutes to destroy the complement and then use it alone or with normal rabbit's, goat's or guinea-pig's serum. Therefore we firmly believe that the complement has no effect upon the charge of the erythrocytes, but it is not easy to say whether the amboceptor or agglutinin acts most effectually on it.

Again normal rabbit's, goat's, or guinea-pig's serum does not cause any change to the charge of rat's erythrocytes, unless the concentration of the serum in the mixture is very great, but if we add to the erythrocytes of the rat the haemolytic serum of a rabbit into which rat's corpuscles have been injected at intervals of a few days, they will show a phenomenon of agglutination and move neither to the anode nor to the cathode in $0,9 \% \mathrm{NaCl}$ solution, so that their negative charge seems to have been neutralized by the haemolytic serum. In this case the complement has nothing to do with the process as in the former case, for we shall obtain the same effect, even if we use the heated haemolytic serum alone or with normal goat's or guineapig's or rabbit's serum.

The erythrocytes of the goat do not show either a phenomenon of agglutination or any remarkable change in their charge when normal rabbit's or guinea-pig's serum, as well as a moderate quantity of the haemolytic serum of a rabbit into which the erythrocytes of the goat have been injected at intervals of a few days is added. But when a very large quantity of the haemolytic serum after having been heated at $56^{\circ} \mathrm{C}$ for 30 minutes in order to eliminate its haemolytic effect by destroying the complement had been added to the erythrocytes of the goat, it was found, that they moved to the anode in $0,9 \% \mathrm{NaCl}$ solution with much less velocity than usual and then

$\equiv$ remained almost stationary, without revealing a sign of agglutination. This fact seems to suggest, that the amboceptor acts upon the erythrocytes more effectually than the agglutinin, as far as the electric charge is concerned. 


\section{SUMMARY.}

1. It is stated that the erythrocytes show a different cataphoresis in the same solution according to the species of the animals and the erythrocytes of the same animal in two different solutions.

2. The erythrocytes of the rabbit possess in $0,9 \% \mathrm{NaCl}$ solution a positive charge unlike those of the other animals, while they are charged in the isotonic sugar solution most negatively charged.

3. The cataphoresis of the erythrocytes was observed under the microscope not only in the $\mathrm{NaCl}$ solution but in many other salt solutions.

4. The statement follows how the cataphoretic phenomena which the erythrocytes show in the isotonic solution of $\mathrm{NaCl}$ or cane-sugar are modified by the addition of several reagents.

5. A test is made showing the change of $\mathrm{pH}$ of different solutions after the addition of the erythrocytes.

6. It is demonstrated that some $\mathrm{Cl}$-ions in solutions of $\mathrm{NaCl}$ or $\mathrm{KCl}$ are taken by the erythrocytes which in turn give off some $\mathrm{HCO}_{3}$-ions.

7. Of all the animals the efficiency of the erythrocytes to raise $\mathrm{pH}$ of some salt solutions, especially of acid salt solutions is the greatest in the rabbit and the least in the dog as far as they were examined.

8. On the other hand the erythrocytes of the rabbit have a weaker efficacy to neutralize an alkaline solution than those of the dog, guinea-pig or goat.

9. While the erythrocytes absorb some $\mathrm{Cl}$-ions in an acid salt solution, they release these in an alkaline salt solution. in.

10. The strong efficiency of the rabbit erythrocytes to raise $\mathrm{pH}$ of some solutions is an important factor, the explanation, perhaps, being that they possess a positive charge in the salt solution unlike those of almost all other animals. Likewise the fact that the erythrocytes of the dog have a strong negative charge in the salt solution seems to bear upon their weak efficacy to neutralize an acid solution. 
11. In order to explain the cataphoresis of the erythrocytes in the sugarsolution a hypothesis is offered concerning the permeability of the membrane of the erythrocytes. If the erythrocytes of the rabbit are thrown into a sugar solution which contains no electrolytes, there would occur a condensation of the cell membrane. so that it would hinder the passage of some anions, while the diffusion of cations goes on unaffected. On the other hand the permeability of the erythrocytes of the dog and cat seems to remain almost unchanged in the sugar solution as well as in the salt solution. For this reason the erythrocytes of the rabbit become in the sugar-solution strongly negatively charged, while those of the dog and cat remain weakly negatively charged.

12. Such solutions as 3,0\% glycerine, $5,0 \%$ d-glucose, $5,0 \%$ laevulose, 9.5\% lactose and 2,0\% glycocoll have the same effect as that of $9,5 \%$ canesugar solution on the cataphoresis of the erythrocytes.

13. The erythrocytes of the rabbit which have a strong power to neutralize an acid solution and are slightly positively charged in $0,9 \% \mathrm{NaCl}$ solution resist the haemolytic effect of the acid more obstinately than those of other animals. On the contrary the crythrocytes of the goat which show a strong negative potential in $0,9 \% \mathrm{NaCl}$ solution are most liable to the haemolysis caused by the acid. Generally speaking it seems probable that erythrocytes which are strongly negatively charged in the $\mathrm{NaCl}$ solution disssolve in an acid solution more easily than those weakly charged.

14. But in a solution of reserve acidity in which some substance acts as "buffer" the erythrocytes of the rabbit are most liable to haemolysis, while those of the goat and dog show a great resistance at least during the first few hours.

15. The erythrocytes of the dog are most easily dissolved in the alkaline solution. With this special exception, the erythrocytes of the rabbit are most liable to haemolysis and those of the goat and rat show the greatest resistance when they are thrown into the solution. Generally speaking it seems probable, that less negatively charged erythrocytes in the $\mathrm{NaCl}$ solution are more liable to the haemolytic effect of the base, the case of the 
dog being cxcluded.

16. Those elements which possess lower solution pressures than hydrogen have generally a strong. power to dissolve or destroy the erythrocytes, and less negatively charged erythrocytes seem to be more liable to haemolysis in solutions of the copper, mercury, silver, gold or platinum compounds.

17. Those elements which possess higher solution pressures than hydrogen have generally only a weak haemolytic effect or none at all, but the trivalent cations $\mathrm{Fe}^{\cdots *}$ and $\mathrm{Al}^{\cdots *}$ are powerful in causing haemolysis, their effect resembling that of the acid.

18. The haemolytic effect of saponin, natrium oleat and alcohol has no bearing on the electric charge of the erythrocytes and seems to be chiefly concerned with the action to dissolve the lipoid.

19. Likewise the haemolysis caused by hypotonic solutions has no relation to the electric charge of the erythrocytes.

20. The resistance of the erythrocytes towards hypotonic $\mathrm{NaCl}$ solutions is increased by the effect of the alkali and decreased by that of the acid (Hamburger). This change is seen very markedly in the goat erythrocytes which have a strong negative potential, while the positively charged erythrocytes of the rabbit in such cases show very little or no change at all.

21. The haemolytic serum has a power to neutralize the charge of the erythrocytes. This action must be attributed to either the amboceptor or agglutinin, the complement having surely nothing to do with it. An experiment on the goat erythrocytes gave a result, which seems to suggest, that the amboceptor acts upon the erythrocytes more effectually than the agglutinin, as far as the electric charge is concerned. 